TI 2011-181/3

Tinbergen Institute Discussion Paper

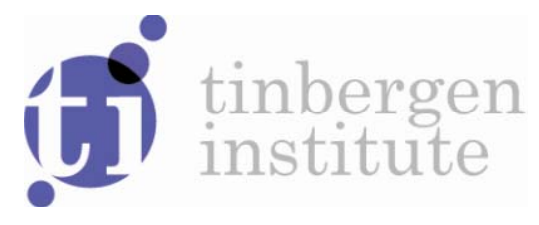

Long-Run vs. Short-Run Perspectives on Consumer Scheduling: Evidence from a Revealed-Preference Experiment among Peak-Hour Road Commuters

Stefanie Peer*

Erik Verhoef:

lasper Knockaert

Paul Koster*

Yin-Yen Tseng*

* Tinbergen Institute. 
Tinbergen Institute is the graduate school and research institute in economics of Erasmus University Rotterdam, the University of Amsterdam and VU University Amsterdam.

More TI discussion papers can be downloaded at http://www.tinbergen.nl

Tinbergen Institute has two locations:

Tinbergen Institute Amsterdam

Gustav Mahlerplein 117

1082 MS Amsterdam

The Netherlands

Tel.: +31(0)205251600

Tinbergen Institute Rotterdam

Burg. Oudlaan 50

3062 PA Rotterdam

The Netherlands

Tel.: +31(0)10 4088900

Fax: $+31(0) 104089031$

Duisenberg school of finance is a collaboration of the Dutch financial sector and universities, with the ambition to support innovative research and offer top quality academic education in core areas of finance.

DSF research papers can be downloaded at: http://www.dsf.nl/

Duisenberg school of finance

Gustav Mahlerplein 117

1082 MS Amsterdam

The Netherlands

Tel.: +31(0)20 5258579 


\title{
LONG-RUN VS. SHORT-RUN PERSPECTIVES ON CONSUMER SCHEDULING: EVIDENCE FROM A REVEALED-PREFERENCE EXPERIMENT AMONG PEAK-HOUR ROAD COMMUTERS*
}

\author{
Stefanie Peer ${ }^{\dagger 1,3}$, Erik T. Verhoef ${ }^{1,2}$, Jasper Knockaert ${ }^{1}$, Paul Koster ${ }^{1,2}$, and Yin-Yen \\ Tseng ${ }^{1,4}$ \\ ${ }^{1}$ Department of Spatial Economics, VU Amsterdam, De Boelelaan 1105, 1081 HV Amsterdam \\ ${ }^{2}$ Tinbergen Institute, Gustav Mahlerplein 117, 1082 MS Amsterdam \\ ${ }^{3}$ Institute for the Environment and Regional Development, Vienna University of Economics and \\ Business, Welthandelsplatz 1, 1020 Vienna, Austria \\ ${ }^{4}$ School of Public Finance and Taxation, Southwestern University of Finance and Economics, \\ Liutai Avenue 555, Wenjiang District, Chengdu, Sichuan 611130, China
}

February 2014

\begin{abstract}
Earlier studies on scheduling behavior have mostly ignored that consumers have more flexibility to adjust their schedule in the long run than in the short run. We introduce the distinction between long-run choices of travel routines and short-run choices of departure times, using data from a real-life peak avoidance experiment. We find that participants value travel time higher in the long-run context, supposedly because changes in travel time can be exploited better through the adjustment of routines. Schedule delays are valued higher in the short run, reflecting that scheduling restrictions are typically more binding in the short run.
\end{abstract}

JEL codes: C25, D03, D80, R48

Keywords: long-run vs. short-run; scheduling decisions; valuation of travel time; valuation of schedule delays; revealed preference data; car travel; peak avoidance

*This study is financially supported by the Dutch Ministry of Infrastructure and the Environment, as well as by the TRANSUMO foundation. Also the financial support from the ERC (Advanced Grant OPTION \#246969) for the research of Paul Koster and Erik Verhoef is gratefully acknowledged. The authors would like to thank Carl Koopmans, Hans Koster and Piet Rietveld for helpful comments.

${ }^{\dagger}$ Corresponding author (E-mail: speer@wu.ac.at) 


\section{Introduction}

Peak-hour traffic congestion is a major problem in most urban areas, causing substantial economic costs. It is driven by the scheduling decisions of individual drivers who share the preference to be at the same place at the same time. When deciding on their departure time they face a well-defined trade-off: if they depart at the beginning or towards the end of the peak, they will encounter modest or no congestion, but arrive at their destination at a time quite different from their preferred arrival time. On the contrary, if they choose a departure time that results in an arrival time close to their preferred arrival time they will face much longer travel times. Vickrey (1969) was the first to model the underlying scheduling dynamics, using an equilibrium model of queuing at a bottleneck. Building on the work of Vickrey and the seminal contributions of Becker (1965) and DeSerpa (1971) on the allocation of time to non-work activities, Small (1982) established a utility function that is still widely used in the modeling of scheduling decisions. He explicitly considers so-called schedule delays, which arise from arriving earlier or later than the desired arrival time, and he provides empirical estimates of travelers' willingness-to-pay for reducing these schedule delays. Based on the early contributions of Gaver (1968), Knight (1974) and Polak (1987) on scheduling behavior when travel times are stochastic, Noland and Small (1995) extended Small's framework to account for scheduling decisions when both peak-congestion and travel time variability are present.

A large number of empirical studies on the willingness-to-pay for reductions in travel time, schedule delays, and travel time variability (the latter causing unexpected schedule delays $^{1}$ ) have been published in the last few decades (e.g. Hendrickson and Plank, 1984; Lam and Small, 2001; Small et al., 2005; Hollander, 2006; Asensio and Matas, 2008). They typically use data on departure time decisions collected from stated preference (SP) or revealed preference (RP) experiments (or both), and estimate the corresponding model parameters using random-utility discrete choice models (McFadden, 1974). Even though the resulting valuations vary widely across studies, they are generally found to be substantial. The value of travel time usually ranges between 20 and 90 percent of the gross wage rate, while the costs of arriving one minute early (late) tend to be lower (higher) than the costs of an additional minute of traveling (e.g. Small and Verhoef, 2007). ${ }^{2}$ These valuations are key input variables for the appraisals of transport policies, where the benefits due to reductions in travel time, schedule delays and variability are often considerably larger than

\footnotetext{
${ }^{1}$ The value attached to reductions of travel time variability is usually referred to as value of reliability, and can either be estimated directly if an indicator of travel time dispersion is included in the utility function, or it can be computed from schedule delay valuations using the analytical results derived by Fosgerau and Karlström (2010).

${ }^{2}$ Literature reviews on the value of time can for instance be found in Shires and De Jong (2009), Wardman (2001), Zamparini and Reggiani (2007) and Small (2012), while the papers of Li et al. (2010) and Carrion and Levinson (2012) contain reviews on scheduling and reliability valuations.
} 
other benefit categories (e.g. Hensher, 2001). ${ }^{3}$ To identify and apply appropriate, possibly context-specific valuations, a good understanding of the underlying scheduling behavior of travelers is thus essential.

This paper proposes a new perspective on scheduling decisions by developing a framework that decomposes scheduling decisions into long-run choices of travel routines, and short-run choices of departure times. Our main goal is to test empirically whether travel times and schedule delays are valued differently in the long run compared to the short run. If this is true, policies that affect short-run scheduling decisions, such as improvements in incident management or provision of travel information, should be evaluated at the values that travelers attach to short-run changes in travel time and schedule delays. On the contrary, long-run oriented measures, such as road capacity expansions, should be evaluated at the values that travelers attach to long-run changes in travel time and schedule delays.

Similar to models of industrial organization (IO) where producers are less constrained in the long run when all input factors are variable than in the short run when at least one input factor is fixed, the models developed and estimated in this paper reflect that commuters typically have more flexibility in adapting their schedules in the longer run than in the shorter run. Routines are thus considered fixed in the short run, but endogenous in the long run. However, unlike in most IO models we also introduce an information component to our model. Specifically, we distinguish between long-run and short-run travel time expectations, taking into consideration that more accurate information on the travel time distribution becomes available only in the short run. In the light of that, drivers may choose for a departure time that results in a different expected arrival time than their routine arrival time. Therefore, in line with the IO literature, the long-run decisions remain fixed in the short run; however, different from most IO models, individuals can deliberately take short-run decisions based on expectations that differ from those underlying their long-run decisions. Such deviations from the long-run routines will only occur if the resulting benefits from short-run travel time gains outweigh the costs that result from the deviation itself.

Most current (empirical and theoretical) scheduling models implicitly assume that successive days are exact replicas in terms of travel times, implying that long-run choices of routines and short-run choices of departure time are identical and cannot be meaningfully disentangled. The same is true for stochastic models when these assume that travel time expectations do not vary between days (hence, when ignoring learning or informationupdating). Also in this case, departure time choices will not be adjusted between days, and again, long-run and short-run behavior coincide. The differentiation between the information available in the long run and the short run is thus an essential part of our

\footnotetext{
${ }^{3}$ For instance, in the evaluation of the London congestion charging scheme, benefits from reductions in travel time account for 77 percent and benefits from improvements in reliability for 10 percent of overall benefits (Evans, 2007). Benefits from reductions in schedule delays have not been quantified.
} 
model, not in the least place for identifying differences between long-run and short-run scheduling behavior.

The definitions we use for the 'long run' and the 'short run' are chosen to best suit the available data on travel behavior. These cover almost 4 months of departure time observations for a set of commuters. Scheduling decisions that are made in the face of attributes that are constant across the 4-month period are referred to as long-run decisions, while decisions that use day-specific attributes as an input are referred to as short-run decisions. Specifically, in the long run drivers choose a routine arrival time, which we refer to as short-run preferred arrival time (SRPAT). The SRPAT minimizes the sum of costs from expected travel time losses and deviations of the SRPAT from the exogenously determined long-run preferred arrival time (LRPAT), and is derived from actual behavior. The LRPAT is defined as the preferred arrival time that would be relevant if no congestion occurred ever. Due to the hypothetical character of such a situation, it is derived from a questionnaire rather than from actual behavior. In the short run, optimal departure times are chosen subject to travel times and deviations of the expected arrival time from the SRPAT. The implied exogenous boundary between the long run and the short run might seem somewhat arbitrary, but may in fact strengthen our results, as it probably leads to a conservative estimate of the difference between long-run and short-run valuations of travel time and schedule delays. ${ }^{4}$

The data used in this study are drawn from a large-scale, revealed-preference (RP) peak avoidance experiment among car commuters in the Netherlands. Participants were able to obtain a daily reward of 4 Euro if they avoided traveling on a specific, frequently congested highway link during morning peak hours. Only few RP experiments that account for scheduling behavior have been conducted so far (e.g. Small, 1982; Lam and Small, 2001; Börjesson, 2008; Knockaert et al., 2012b), mainly because the derivation of willingness-topay estimates from RP data does not only require a real-life situation where the monetary attribute (a toll or a reward) varies over the time of the day, but also high-quality data on the attributes of the chosen and unchosen scheduling choice alternatives. While the collection of corresponding stated preference (SP) data would have been less demanding, we expect that the use of SP data and in particular their hypothetical character would have made it more difficult or even impossible to distinguish between the long-run and the short-run dimension. Besides the fact that the dataset we use in this paper is based on $\mathrm{RP}$ data, it is also rather unique in having a panel structure, which is an indispensable feature for identifying long-run behavior. Moreover, detailed travel time data are available, which allow us to construct distinct long-run and short-run travel time expectations for

\footnotetext{
${ }^{4}$ Alternative definitions of the long and short-run are certainly imaginable. For instance, it is possible to endogenize the structural arrival time preferences and let them depend on job choices as well as residential and work locations choices. Some studies that focus on such choices also determine valuations of travel time (e.g Van Ommeren et al., 2000; Van Ommeren and Fosgerau, 2009). However, the resulting values are usually not directly comparable to the values derived in this paper, not in the last place because most of them do not distinguish between travel-time- and scheduling-related costs.
} 
all possible scheduling alternatives at a door-to-door level. We can thus avoid the use of reported travel time data, which are often imprecise or even biased (e.g Small and Verhoef, 2007, p.21).

We use discrete choice models to analyze the participants' choices of routines and departure times. We find that drivers value more permanent (long-run) travel time gains substantially higher than short-run gains, presumably because these can be exploited better through the adjustment of routines. After all, a structural time gain of one minute can typically be used more effectively than an incidental gain of the same size. This result is consistent with the results obtained by Tseng et al. (2013), who find that the value attached to a permanent one-hour travel time gain is 14.5 Euro/hour, compared to 3 Euro/hour for an incidental travel time gain of one hour. On the other hand, we find a substantially higher value attached to less permanent (short-run) changes of schedule delays, with the difference mounting to an order of two to three. This finding is consistent with the notion that scheduling restrictions are normally more binding in the short run. Börjesson (2009) and Börjesson et al. (2012) speculate along similar lines to explain the differences they find between the valuation of planned and unplanned delays in models that are based on SP data and do not distinguish between short-run and long-run values of time and schedule delays.

Our results strongly suggest that individuals apply some sort of inter-temporal optimization that leads to differences in long-run and short-run preferred arrival times and the valuations of travel time and schedule delays. This is a clear indication that the valuations are strongly context-dependent, and the application of the valuations, for instance in the appraisal of transport policies, should thus be context-dependent as well. Moreover, we speculate that the large dispersion of the values of time and of schedule delay that is found in the literature may partially be explained by differences in the relative prominence of long-run and short-run definitions of choice variables and model attributes. However, the differentiation between short-run and long-run scheduling decisions is not only relevant in an empirical research context, but has also important implications for equilibrium models of travel behavior, as used to assess the social desirability of infrastructure investments or road pricing. For example, Peer and Verhoef (2013) obtain the intriguing result that the application of first-best short-run tolls does not induce efficient long-run choices of travel routines. They make use of Vickrey's bottleneck model and assume a preference structure that is consistent with the valuations obtained in this paper.

The outline of the paper is as follows. In Section 2 we introduce the modeling framework, specifically the distinction between the long-run and the short-run scheduling model, and discuss how they are interrelated. Section 3 gives an overview of the data, including the experimental setup and variable definitions. The estimation results as well as several robustness checks are presented in Section 4. Section 5 concludes the paper. 


\section{Modeling framework}

\section{$2.1 \quad$ Introduction}

In the conventional scheduling model, as introduced by Vickrey (1969) and operationalized for estimation by Small (1982), the utility of departing at a specific time $t$ depends linearly on the corresponding monetary attribute (a toll or reward) $R_{t}$, travel time $T_{t}$, and the extent of earliness or lateness with respect to the preferred arrival time. ${ }^{5}$ The last two attributes are generally referred to as schedule delay early, $\mathrm{SDE}_{t}$, and schedule delay late, $\mathrm{SDL}_{t}$. The coefficients attached to these attributes are then denoted by $\beta_{R}, \beta_{T}, \beta_{E}$ and $\beta_{L}$, respectively. The reward coefficient $\beta_{R}$ indicates the marginal utility of income (if $R_{t}$ is defined as reward rather than a cost), whereas $-\beta_{T},-\beta_{E},-\beta_{L}$ indicate the marginal utility gained from reductions in travel times and schedule delays, respectively. The value of (travel) time (VOT) is thus defined as $-\beta_{T} / \beta_{R}$, and the values of schedule delay early (VSDE) and late (VSDL) by $-\beta_{E} / \beta_{R}$ and $-\beta_{L} / \beta_{R}$, respectively.

While adhering closely to these notations, we adapt the standard scheduling model in such a way that we are able to study differences between long-run and short-run scheduling behavior. The main underlying idea is that in the long run, arrival routines are chosen subject to structural arrival time preferences, whereas in the short run departure times are chosen subject to the arrival routines that result from maximizing the long-run utility. In the terminology that we will use, the structural arrival time preference is referred to as long-run preferred arrival time (LRPAT), and the long-run utility maximizing arrival time as short-run preferred arrival time (SRPAT). Schedule delays in the long-run model are therefore defined as deviations of the routine arrival time from the LRPAT, while schedule delays in the short-run model are defined as deviations of the daily arrival time from the SRPAT. Moreover, we make (and later on test) the assumption that the availability of information on travel times differs between the long and the short run. More specifically, in the long run only average traffic conditions are known, whereas in the short run more information on actual travel time realizations becomes available.

To give an example: in a world without traffic congestion, a driver's preferred arrival time at work may be 9:00 a.m. (his LRPAT), whereas recurring congestion may induce him to organize his routines such that he aims to arrive already at 8:00 a.m. (his SRPAT), when less congestion is present on average. As a consequence, he may make appointments at work earlier, and given those appointments, he will consider 8:00 a.m. as his preferred arrival time when choosing his departure time on a given day. That is, if the preferred arrival time under uncongested conditions is at 9:00 a.m., but the driver has organized

\footnotetext{
${ }^{5}$ Small's original model also includes a 'late dummy' that indicates a discrete jump in utility for late arrivals. If travel times are stochastic (as in this paper), this variable represents the probability of lateness. However, the value attached to it tends to be fairly low once scheduling variables are included in the model (e.g. Small, 1999), which is why we do not consider it here.
} 
routines such that he expects to arrive around 8:00 and therefore plans a meeting at 8:15, a delayed arrival at 8:30 brings (short-run) schedule delay late, not early.

The main focus of this paper is to test wether long-run and short-run valuations of travel times and schedule delays diverge. For this purpose, we estimate two basic choice models, which explain the long-run choices on routine arrival time and the short-run choices on departure times, respectively, using variations in (expected) rewards, travel times and schedule delays over the time of the day for identification. Furthermore, an auxiliary model is defined that aims at testing the assumption that in the short run, the SRPAT is the relevant anchor point for scheduling decisions (rather than the LRPAT). All three models are discussed below in detail.

\section{$2.2 \quad$ Long-run model}

The long-run model explains the choice of a routine arrival times $a$, for each driver $z=1, \ldots, Z$ and weekday $l=1, \ldots, 5$. Note that we refer to the chosen (and hence utility-maximizing) routine as short-run preferred arrival time (SRPAT). Arrival routines as well as travel time expectations are both defined as weekday-specific, since travel times differ substantially across weekdays, and drivers can therefore be expected to adapt their arrival routines accordingly. As in the conventional scheduling model, the utility associated with arrival routine $a$ then depends on the expected reward, the expected travel time, and the schedule delays. The long-run expectation operator applied to the reward and the travel time attribute is denoted by $E[.]^{L R}$ and will be further specified below. Schedule delays, in contrast, are deterministic as they represent the deviations of $a$ from the LRPAT. The indirect utility $V_{z l a}^{L R}$, can then be written as:

$$
\begin{array}{r}
V_{z l a}^{L R}=\beta_{R} E\left[R_{z l a}\right]^{L R}+\beta_{T} E\left[T_{z l a}\right]^{L R}+\beta_{E} \mathrm{SDE}_{z l a}+\beta_{L} \mathrm{SDL}_{z l a} \\
\text { where } \mathrm{SDE}_{z l a}=\max [\mathrm{LRPAT}-a, 0] \\
\mathrm{SDL}_{z l a}=\max [a-\mathrm{LRPAT}, 0]
\end{array}
$$

We do not include a term that represents travel time variability in the utility function, since we find that travel time and travel time variability (defined as the standard deviation of the travel time distribution) are heavily positively correlated, and can thus not be estimated separately. One of the robustness checks undertaken in this paper aims at separating these two cost components by approximating the costs associated with travel time variability using the analytical results of Fosgerau and Karlström (2010).

We define the long-run expectation for attribute $A \in\{R, T\}$ on weekday $l$ as the average attribute value on that weekday over a time period of $k=1, \ldots, K$ days (i.e. the duration of the experiment). The long-run expectation for attribute $A, E\left[A_{z l a}\right]^{L R}$, is then given by 


$$
E\left[A_{z l a}\right]^{L R}=\frac{\sum_{k=1}^{K} A_{z l a} \mathbf{1}_{\{\operatorname{weekday}(k)=l\}}}{\sum_{k=1}^{K} \mathbf{1}_{\{\operatorname{weekday}(k)=l\}}},
$$

where the indicator function $\mathbf{1}_{\{\text {weekday }(k)=l\}}$ is equal to 1 if it is true that day $k$ corresponds to weekday $l$, and 0 otherwise. Equation 2 thus implicitly assumes that drivers have information about future travel time realizations when choosing their optimal arrival routine (the SRPAT). While it is impossible to know the travel time realizations ex ante, the average weekday-specific travel time seems to be a good representation of the expectation a regular commuter may have about travel time realizations, including those in the future.

\subsection{Short-run model}

The optimal arrival time chosen in the long-run model $\left(\arg \max E\left[V_{z l a}\right]^{L R}\right)$ is fixed in the short run, and becomes the relevant preferred arrival time in the short-run scheduling decisions: the SRPAT. In the short run, the $z=1, \ldots, Z$ drivers choose a departure time $t$ on a series of days $k=1, \ldots, K$. The short-run utility function, $V_{z k t}^{S R}$, is again a linear function of expected rewards, travel times and schedule delays. In contrast to the long-run model, all attributes are stochastic, and the expectation operator for the short run is denoted by $E[.]^{S R}$. Note that the short-run model assumes that the disutility of travel time variability is entirely captured by its impact on expected schedule delay costs.

$$
\begin{array}{r}
V_{z k t}^{S R}=\beta_{R} E\left[R_{z k t}\right]^{S R}+\beta_{T} E\left[T_{z k t}\right]^{S R}+\beta_{E} E\left[\mathrm{SDE}_{z k t}\right]^{S R}+\beta_{L} E\left[\mathrm{SDL}_{z k t}\right]^{S R} \\
\text { where } E\left[\mathrm{SDE}_{z k t}\right]=E\left[\max \left[\mathrm{SRPAT}-t-T_{z k t}, 0\right]\right] \\
E\left[\mathrm{SDL}_{z k t}\right]=E\left[\max \left[t+T_{z k t}-\mathrm{SRPAT}, 0\right]\right]
\end{array}
$$

In the short run, more up-to-date information on travel time realizations becomes available compared to the long run, for instance due to better knowledge of upcoming weather conditions. We represent this enhanced information availability by computing a weighted average of the long-run expectation of attributes $A \in\{R, T, \mathrm{SDE}, \mathrm{SDL}\}$ (the weekday-specific averages) and the regarding attribute value based on the actual travel time realization on the day of travel $\bar{k} \in K$. The weight attached to the actual travel time realizations, relative to the long-run travel time expectations, is denoted by $\theta$ and will be estimated. ${ }^{6}$ We use an indicator function similar to the one employed in the long-run model, $\mathbf{1}_{\{\text {weekday }(k)=\bar{l}\}}$, to indicate whether the weekday corresponding to $k$ also corresponds to

\footnotetext{
${ }^{6}$ We also tested alternative methods (i.e. state-space and semi-parametric estimations) that allowed the expected travel times to depend on day-specific variables such as weather conditions. However, we found that the difference between realized and expected travel times barely decreased as a consequence of adding
} 
weekday $\bar{l}$, where $\bar{l}$ indicates the weekday associated with the day of travel $\bar{k}$ :

$$
E\left[A_{z \bar{k} j}\right]^{S R}=\theta A_{z \bar{k} j}+(1-\theta) \frac{\sum_{k=1}^{K} A_{z k j} \mathbf{1}_{\{\operatorname{weekday}(k)=\bar{l}\}}}{\sum_{k=1}^{K} \mathbf{1}_{\{\operatorname{weekday}(k)=\bar{l}\}}}
$$

Although it is unrealistic that the actual travel times are known to drivers at the moment of departure, they represent an objectively measurable benchmark for the maximum extent of information they may have at the time of departure.

\subsection{Auxiliary model}

Besides the basic long-run and short-run models specified by Equations 1 and 3, we introduce an alternative short-run model, which is used to test whether it is true that the SRPAT is indeed the relevant anchor point in departure time decisions, as stated in Equation 3. If this is true, a move away from the SRPAT towards the LRPAT would increase schedule delay costs. We therefore re-formulate the short-run model by changing the definition of the schedule delays such that it becomes possible to determine whether scheduling costs are at their minimum at the SRPAT or at the LRPAT. To do so, we introduce the adapted schedule delays SDAE and SDAL, which capture arrival moments that are early or late with respect to both measures of SRPAT and LRPAT. In addition, we define the intermediate domains SDME and SDML. SDME captures arrival moments that are early with respect to the SRPAT but late with respect to the LRPAT, provided that LRPAT < SRPAT. Likewise, SDML captures arrival moments that are late with respect to the SRPAT but early with respect to the LRPAT, provided that LRPAT $\geq$ SRPAT. The corresponding utility in this auxiliary model is denoted by $V_{z k t}^{\mathrm{AUX}}$, and the travel time expectations are defined in the same way as in the short-run model (Equation 4):

$$
\begin{array}{r}
V_{z k t}^{\mathrm{AUX}}=\beta_{R} E\left[R_{z k t}\right]^{S R}+\beta_{T} E\left[T_{z k t}\right]^{S R}+\beta_{E} E\left[\mathrm{SDAE}_{z k t}\right]^{S R}+\beta_{L} E\left[\mathrm{SDAL}_{z k t}\right]^{S R}+ \\
\beta_{M E} E\left[\mathrm{SDME}_{z k t}\right]^{S R}+\beta_{M L} E\left[\mathrm{SDML}_{z k t}\right]^{S R} \\
\text { where }
\end{array}
$$

\begin{tabular}{lll} 
& LRPAT $<$ SRPAT & LRPAT $\geq \mathrm{SRPAT}$ \\
\hline $\mathrm{SDAE}_{z k t}=$ & $\max \left[\mathrm{LRPAT}-t-T_{z k t}, 0\right]$ & $\max \left[\mathrm{SRPAT}-t-T_{z k t}, 0\right]$ \\
\hline $\mathrm{SDAL}_{z k t}=$ & $\max \left[t+T_{z k t}-\mathrm{SRPAT}, 0\right]$ & $\max \left[t+T_{z k t}-\mathrm{LRPAT}, 0\right]$ \\
\hline $\mathrm{SDME}_{z k t}=$ & $\begin{array}{l}\min [\mathrm{SRPAT}-\mathrm{LRPAT}, \\
\left.\max \left[\mathrm{SRPAT}-t-T_{z k t}, 0\right]\right]\end{array}$ & 0 \\
\hline $\mathrm{SDML}_{z k t}=$ & 0 & $\begin{array}{l}\min [\mathrm{LRPAT}-\mathrm{SRPAT}, \\
\left.\max \left[t+T_{z k t}-\mathrm{SRPAT}, 0\right]\right]\end{array}$ \\
\hline
\end{tabular}

these variables. This can probably be attributed to the fact that we consider travel times over a period of less than 4 months, during which weather conditions and seasonal demand patterns were fairly stable. 
Consider the case when SRPAT $\leq$ LRPAT: if $\beta_{M L}$ would be equal to $\beta_{L}$, the model would suggest that the SRPAT is the relevant anchor to describe short-run behavior, and the LRPAT has no influence whatsoever in the short-run model. In contrast, when $\beta_{M L}=-\beta_{E}$, the model suggests that the LRPAT is the relevant anchor point, and the SRPAT has no impact on short-run choices. We may expect $\beta_{M L}$ to be somewhere between these polar cases, and would take a significant negative sign as an indicator of the desirability of an arrival at the SRPAT over an arrival at the LRPAT. A similar argument can be made for the case where LRPAT $<$ SRPAT.

If both $\beta_{M L}$ and $\beta_{M E}$ are negative (just as $\beta_{L}$ and $\beta_{E}$ are expected to be), we can confirm that deviations from the SRPAT towards the LRPAT indeed increase scheduling costs. The auxiliary model therefore helps identifying the extent to which the SRPAT rather than the LRPAT determines short-run scheduling behavior.

\subsection{Econometric specifications}

The three models discussed above can be estimated employing the additive randomutility model developed by McFadden (1974). It assumes that choices between discrete alternatives are made such that the random utility of the decision maker is maximized. As a consequence, the continuous long-run, short-run and auxiliary choice problems as outlined in Equations 1, 3 and 5 must be re-formulated as a discrete problem with a finite number of choice alternatives $j=1, \ldots, J$. The corresponding subscripts of the utility $V$ thus change from $z l a$ to $z l j$ in the long-run model, and from $z k t$ to $z k j$ in the short-run and the auxiliary model, where $j$ represents the index number associated with an arrival time interval $a$ in the long-run model and a departure time interval $t$ in the short-run and auxiliary models. The random error term corresponding to the long-run model is then denoted by $\epsilon_{z l j}$, and the error terms corresponding to the short-run and the auxiliary model by $\epsilon_{z k j}$. We apply a standard discrete-choice specification and assume that the random terms are additive and iid with the extreme-value distribution. From these assumptions, the multinomial logit (MNL) model arises, and the choice probabilities for alternative $i \in J, P_{z l i}^{L R}, P_{z k i}^{S R}$ and $P_{z k i}^{A U X}$, have the logit form:

$$
P_{z l i}^{L R}=\frac{\exp \left(V_{z l i}^{L R}\right)}{\sum_{j=1}^{J} \exp \left(V_{z l j}^{L R}\right)}, \quad P_{z k i}^{S R}=\frac{\exp \left(V_{z k i}^{S R}\right)}{\sum_{j=1}^{J} \exp \left(V_{z k j}^{S R}\right)} \quad \text { and } \quad P_{z k i}^{A U X}=\frac{\exp \left(V_{z k i}^{A U X}\right)}{\sum_{j=1}^{J} \exp \left(V_{z k j}^{A U X}\right)}
$$

The model parameters can then be estimated by maximizing the corresponding loglikelihood function, which is defined as the sum of the logs of the choice probabilities of the chosen alternatives across observations. Because arrival routines are weekday-specific and departure time decisions are made on numerous days, multiple observations per driver are included in the long-run as well as short-run datasets. The MNL model ignores this panel nature of the datasets. The assumption of independent observations is probably less drastic for RP data compared to SP data, as the valuation attached to travel time and 
schedule delays may differ across days also for a given driver. In order to correct for a possible under-estimation of the standard errors, the panel specification of the sandwich estimator is used (e.g Daly et al., 2013).

Moreover, we will test whether our results still hold if the models allow for heterogeneity across drivers. For this purpose, we re-estimate the main models using panel latent-class models. These models assume that drivers can be sorted into a set of $Q$ classes, with (some or all) coefficient estimates being class-specific. The term 'latent' derives from the fact that preference heterogeneity is unobserved. So, it is ex ante unknown to the analyst to which class a particular driver belongs to, and also after the estimation only membership probabilities rather than actual memberships are derived. The analyst only has control over the number of classes $Q$. The estimation procedure differs from the estimation of MNL models mainly by the fact that not only choice probabilities for the alternatives $j=1, \ldots, J$ need to be determined, but also the probabilities of being member of class $q=1, \ldots, Q$. In line with the notation used by Greene and Hensher (2003), these are denoted by $H_{z q}$. The loglikelihood function for the long-run model is then given by the following equation:

$$
\ln L=\sum_{z=1}^{Z} \ln \left[\sum_{q=1}^{Q} H_{z q}\left(\prod_{l=1}^{l=5} \bar{P}_{z l \mid q}\right)\right],
$$

where $\bar{P}_{z l \mid q}$ is equal to the probability associated with the chosen arrival routine by driver $z$ on weekday $l$ conditional on driver $z$ being member of class $q$. And the multiplicative term $\prod_{l=1}^{l=5} \bar{P}_{z l \mid q}$ therefore represents the likelihood of the sequence of arrival routine choices for each weekday $l$ made by driver $z$, again conditional on class membership. Similarly, a latent class version of the short-run model can be established.

Latent class models can be considered a special case of mixed logit models. The essential difference between them is that mixed logit models capture unobserved heterogeneity by estimating a continuous probability density function for the parameters, whereas latent class models assume a discrete distribution. Latent class models have the advantage that they do not require distributional assumptions regarding heterogeneity. The analyst only needs to specify the number of classes. Given the limited number of classes that are distinguished in most applications, an instructive and intuitive representation of heterogeneity can be achieved. Moreover, a latent class setting usually allows all relevant coefficients to vary across classes, even if the variation in explanatory variables is low and correlation between the variables is high, whereas mixed logit models tend to be more restrictive in this respect. This is mainly because in contrast to mixed logit models, a closed expression for the log-likelihood estimator is available for latent class models, enabling the estimation of more coefficients with the same amount of computational resources. For these reasons, panel latent class models are used in this paper as a simple, yet insightful check for the effects of unobserved heterogeneity across drivers. 


\section{Data}

\subsection{Experimental setting}

We use RP data that were collected during a large-scale peak avoidance (Spitsmijden in Dutch) experiment in the Netherlands. ${ }^{7}$ Participants were eligible for a monetary reward of 4 Euro per day if they avoided traveling on a specific highway $\operatorname{link}^{8}$ during the morning peak (6:30-9:30 a.m.). The highway link has a length of $9.21 \mathrm{~km}$ and is frequently congested during morning peak hours. We refer to the link as 'C1-C2', since it is defined as the road segment between two cameras ' $C$ '. Rewards could not be earned on weekends or school vacation days, and when a driver had already exceeded the maximum number of rewards per 2-week period. This maximum is driver-specific, and is based on a driver's reference behavior, which is defined as the average number of trips he had undertaken along the C1-C2 link per 2-week period before the start of the experiment. ${ }^{9}$

The entire experiment lasted for more than a year, from November 2008 until December 2009. Participants could join and leave the experiment during this period. Overall, about 5000 commuters participated. More than 15000 commuters had been invited to participate in the experiment after they were observed passing the $\mathrm{C} 1-\mathrm{C} 2$ link regularly, resulting in almost 3000 actual participants. Another 2000 participants were recruited through lease car companies and from an earlier peak avoidance experiment, or applied spontaneously for participation. The selection of the participants is therefore voluntary and not random. In a robustness check, we will test possible implications of the self-selection on the distinction between long-run and short-run scheduling behavior.

Travel times and passage times of the participants have been measured directly along the $\mathrm{C} 1-\mathrm{C} 2$ link, using cameras capable of number plate detection. For our analysis, we prefer to use door-to-door travel times instead. The underlying intuition can be found in an accompanying paper (Peer et al., 2013), and is briefly summarized here. It relates to the frequent finding that travel times are correlated positively across links, for instance because speeds are low on large parts of the network during peak periods. If these correlations are ignored in a scheduling model (as it would be the case if only travel times along the C1-C2 link instead of door-to-door travel times were taken into account), differences between peak and off-peak travel times will be underestimated, and consequently the value of time will be overestimated. In order to avoid this, Peer et al. (2013) develop a method based on geographically weighted regression (GWR) to approximate driver-, dayand time-of-day-specific door-to-door travel times as well as departure times from home and arrival times at work. More specifically, they estimate travel time correlation across

\footnotetext{
${ }^{7}$ A more detailed overview of this experiment can be found in Knockaert et al. (2012a).

${ }^{8}$ Highway A12 between Gouda and Zoetermeer with driving direction towards The Hague.

${ }^{9}$ For roughly 9 percent of the observed travels, participants were not able to earn a reward regardless of their passage time of the $\mathrm{C} 1-\mathrm{C} 2 \mathrm{link}$, as they had already exceeded their maximum number of rewards.
} 
links, taking into account that these correlations vary over space, and thus depend on the home and work location of a driver. The same method is also used to approximate the door-to-door travel times for the analyses conducted in this paper.

In this paper, we focus on drivers who participated in the experiment between begin September 2009 and mid December 2009 ( $K=75$ working days), and who were observed to use the C1-C2 link at least occasionally during that time period. From these participants, only those are selected who filled in a survey that included questions about their long-run arrival time preference, and for whom we are able to approximate door-to-door travel times given the limited coverage of the GPS-based GWR model developed in Peer et al. (2013). These restrictions leave use with $Z=371$ drivers.

\subsection{Operationalization of the LRPAT and the SRPAT}

For each driver, measures of the LRPAT and the SRPAT need to be determined. We derive the LRPAT from reported data and the SRPAT from actual behavior. By nature of its definition, the LRPAT refers to a guaranteed congestion-free situation, and can therefore not be derived from actual behavior. Instead, the LRPAT is obtained from a questionnaire conducted among the participants of the experiment. They were asked to state their preferred arrival time at work if they knew for sure that they would not face any congestion during their commuting trip. ${ }^{10}$

The SRPAT on the other hand is defined as the driver- and weekday-specific median arrival time at work. ${ }^{11}$ When estimating the short-run model, we will exclude those choices for which the actual arrival time by definition coincides with the corresponding SRPAT, as these choices are clearly endogenous: the SRPAT is supposed to explain the actual arrival time, but the median actual arrival time in fact defines the SRPAT. We do not expect the procedure of removing the median arrival times to cause biased estimates, as it is essentially identical to the unsuspicious procedure of removing a random set of departure time choices (one per driver) and setting the arrival times that correspond to each of the removed choices equal to the scheduling anchor for the remaining choices of that particular driver. It is of minor importance that the choices yielding the median arrival times are removed rather than a random set of choices, at least if one is willing to accept our modeling assumption that drivers have a stable utility function. The underlying preferences for the trade-off between reward, travel time, schedule delays are thus the same on each day, implying that drivers do not have different preferences on the day associated with the median than on other days. Only if they would, we would expect biased estimates. Also, the removed choices are not substantially different from the included ones (except

\footnotetext{
${ }^{10}$ Drivers with a LRPAT earlier than 6:30 or later than 9:30 were removed from the dataset as these drivers do not have an incentive to travel during the peak period, meaning that the trade-offs modeled in the long-run and short-run utility functions are irrelevant to them.

${ }^{11}$ If the number of observations per driver and weekday is an even number, we randomly assign one of the two middle values as median.
} 
for being slightly more clustered towards the middle of the peak in terms of arrival time). Finally, it is reassuring that the results of the short-run model do not change much if the choices corresponding to the median arrival times are kept in the dataset. Note that we do not specify the SRPAT as average arrival time as this would mean that in the short-run model all observations are subject to endogeneity, as all arrival times would have an impact on the SRPAT from which they are in turn explained. Moreover, it can be shown that the fit of the long-run model decreases if the SRPATs are defined as mean rather than median arrival times, possibly because the mean is overly affected by outliers.

Based on the specification of the long-run model, it is clear that the LRPAT is the relevant anchor point for the long-run scheduling decisions. For the short-run model, it is the SRPAT. But the empirical specification in the latter case is less obvious. One could establish a direct link between the long-run and the short-run model by using the fitted SRPATs (as estimated in the long-run model) rather than the 'actual' SRPATs (the medians). However, this would mean that the available information on the 'actual' SRPATs is ignored in the short-run model. The consequence becomes immediately visible if the approach is pursued: the explanatory power of the short-run model drops significantly. For this reason, we adhere to using the 'actual' SPRATs (as defined above) as relevant scheduling anchor in the short-run model.

\subsection{Choice set definitions and descriptives}

For both the long-run and the short-run models, the choice set consists of $J=16$ discrete and distinct choice alternatives. Each alternative corresponds to a 15-minute interval. In the long-run model, a driver is able to choose between arrival routines that result in an arrival time at work between 6:15 and 10:00. In the short-run model, the choice set is driver-specific. This is to ensure that despite the differences in home-work distances only the most relevant departure time alternatives are included for each driver ${ }^{12}$, in particular those that yield a trade-off with respect to the reward. For each driver the short-run choice set contains 12 departure time alternatives that result (in expected terms) in a passage time of the $\mathrm{C} 1-\mathrm{C} 2$ link during the peak, and therefore do not yield a reward, and 4 alternatives that result, again in expected terms, in an off-peak passage time of the $\mathrm{C} 1-\mathrm{C} 2$ link ( 2 alternatives before, and 2 after the peak). Following these definitions, the choice set can be considered exhaustive. Due to data limitations we are not able to estimate a model that takes into account also other potentially available choice alternatives, including alternative transport modes and routes, or the possibility to work from home, which some of the participants might have.

Table 1 provides some descriptive statistics on the datasets used for the estimation of the long-run and the short-run models. The number of observations in the long-run model

\footnotetext{
${ }^{12}$ A driver-specific choice set is less relevant for the long-run model, since travel distances between $\mathrm{C} 2$ and work are rather similar across drivers (compared to the home-C1 distances), and hence a given set of arrival alternatives captures similar trade-offs between reward and travel time for all drivers.
} 
is determined by the number of driver-weekday combinations for which valid measures of the SRPAT are available. For the SRPAT to be available for a given driver and weekday, the driver must have been observed to pass the $\mathrm{C} 1-\mathrm{C} 2$ link on that specific weekday at least three times (during days he was eligible for receiving a reward). The driver-specific average number of weekdays for which the SRPAT can be specified, given this restriction, is around 3. The short-run dataset then consists of all observations that were used in determining the SRPAT, except for the ones for which the corresponding arrival times have been identified as SRPAT (resulting in an exclusion of 1306 observations). We find that the average remaining number of departure time choices per driver is about 16. Table 1 also gives an overview of the short-run schedule delays, showing that more than 60 percent of the departure time choices result in an arrival time that is less than 15 minutes early or late with respect to the SRPAT. Finally, the distribution of the monthly net household income of the participants is presented. The available figures clearly indicate that the participants can dispose of a higher net household income than the average Dutch household (ca. 2760 Euro in 2008)..$^{13}$

Figure 1a provides the intuition behind defining travel time expectations and routines as weekday-specific. It demonstrates that travel times differ substantially across weekdays. Figure $1 \mathrm{~b}$ contains a scatterplot for all drivers and weekdays for which valid measures of the SRPAT and the LRPAT are available. As expected, given that travel times follow a pronounced peak pattern, the distribution of the SRPAT is relatively more dispersed over time-of-day than the distribution of the LRPAT, which peaks roughly between 8:00 and 9:00. More specifically, drivers with a relatively early LRPAT (the median LRPAT is indicated in the figure) tend to choose a SRPAT that is earlier than their LRPAT, while drivers with a relatively late LRPAT tend to choose a later SRPAT. The differences in the distribution of the LRPAT and the SRPAT are confirmed by their corresponding histograms, shown in Figures 1c and 1d. Since rewards can be gained for passing C1-C2 before 6:30, a very pronounced peak can be observed for arrival times at work between 6:30 and 7:00. ${ }^{14}$ The figures thus provide a strong indication that the choice of the SRPAT is indeed the result of a trade-off between the average congestion pattern, deviations from the LRPAT, as well as the distribution of the monetary incentive over time of the day.

\footnotetext{
${ }^{13}$ The average annual net income amounts to 33.100 Euro: http://statline.cbs.nl/StatWeb/ publication $/$ ?DM $=$ SLNL\&PA $=71511$ ned\&D $1=a \& D 2=a \& D 3=0 \& D 4=a \& V W=T$

${ }^{14}$ In one of the sensitivity analyses to be presented below, we will weight observations to correct for possible biases that may result from this peak.
} 
Table 1: Descriptives datasets

\begin{tabular}{lcc} 
Variables & Value & St. Dev. \\
\hline General & 75 & - \\
Nr. of days $(K)$ & 371 & - \\
Nr. of drivers $(Z)$ & 16 & - \\
Nr. of choice alternatives $(J)$ & & \\
\hline Long-run dataset & 1158 & - \\
Nr. of SRPAT choices & 3.12 & 1.42 \\
Avg. nr. of SRPAT choices per driver & & \\
\hline Short-run dataset & 7271 & - \\
Total nr. of departure time choices & 1306 & - \\
Nr. of excluded choices due to coincidence of SRPAT and arrival time & 5965 & - \\
Remaining nr. of departure time choices & 16.08 & 11.21 \\
Avg. remaining nr. of departure time choices per driver & & \\
\hline Arrival time deviations from the SRPAT & $7.66 \%$ & - \\
more than 30 minutes early & $11.03 \%$ & - \\
between 15 and 30 minutes early & $62.35 \%$ & - \\
between 15 minutes early and 15 minutes late & $9.64 \%$ & - \\
between 15 and 30 minutes late & $9.32 \%$ & - \\
more than 30 minutes late & & \\
\hline Monthly net income per household & $5.99 \%$ & \\
$<2000$ Euro & $26.70 \%$ & \\
2000-3500 Euro & $30.52 \%$ & \\
3500-5000 Euro & $14.44 \%$ & \\
>5000 Euro & $22.34 \%$ & \\
no information &
\end{tabular}




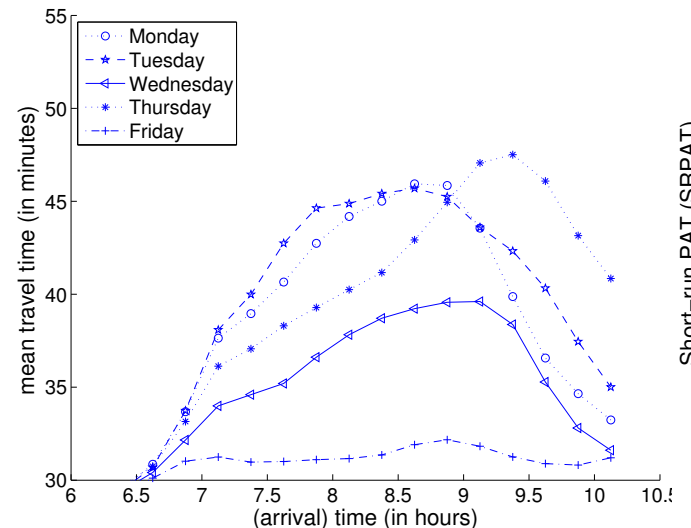

(a) Average weekday-specific travel times

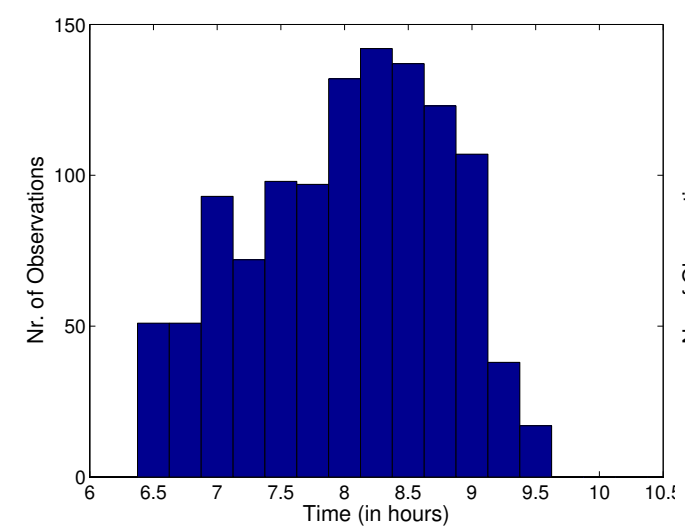

(c) Histogram LRPAT

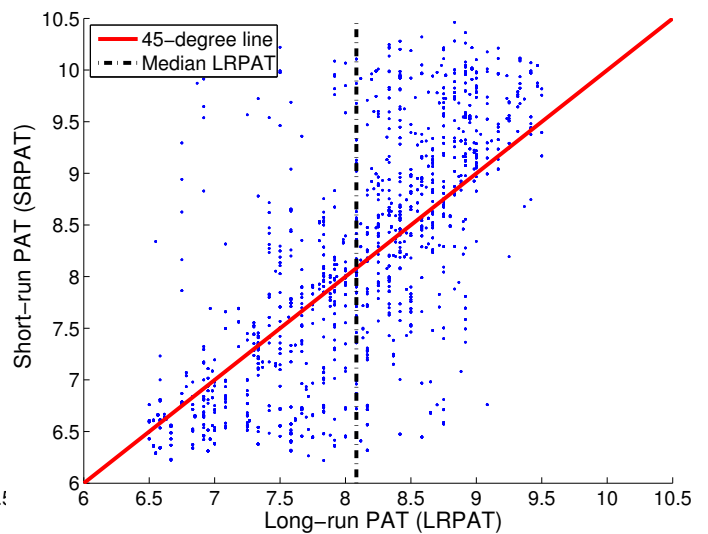

(b) Scatter LRPAT vs. SRPAT

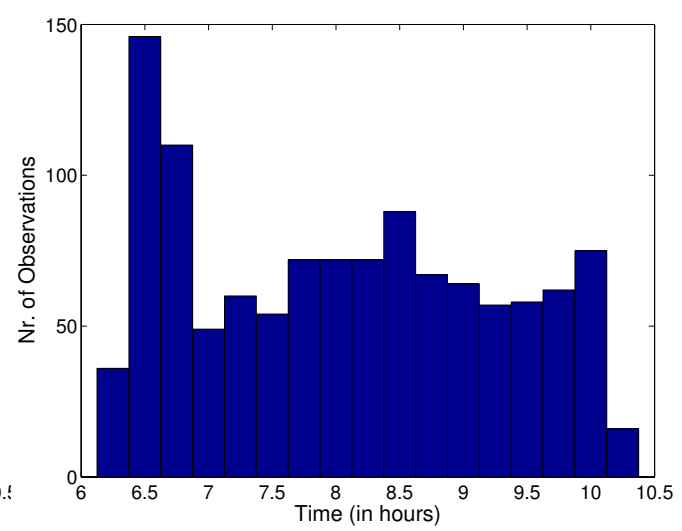

(d) Histogram SRPAT

Figure 1: Descriptives LRPAT and SRPAT 


\section{Estimation results}

\subsection{Main models}

Table 2 shows the results obtained for the long-run, the short-run and the auxiliary model.

Table 2: Results: Main models (MNL)

\begin{tabular}{|c|c|c|c|c|c|c|}
\hline \multirow[b]{2}{*}{ Coefficient } & \multicolumn{2}{|c|}{ Long-Run } & \multicolumn{2}{|c|}{ Short-Run } & \multicolumn{2}{|c|}{ Auxiliary } \\
\hline & Value & t-Statistic & Value & t-Statistic & Value & t-Statistic \\
\hline$\beta_{R}$ & 0.22 & 5.02 & 0.13 & 5.78 & 0.17 & 6.75 \\
\hline$\beta_{T}$ & -6.61 & -7.33 & -0.69 & -1.45 & -1.75 & -3.09 \\
\hline$\beta_{E}$ & -2.06 & -13.39 & -2.89 & -18.38 & -3.83 & -14.52 \\
\hline$\beta_{L}$ & -1.58 & -13.99 & -2.70 & -20.34 & -2.53 & -20.80 \\
\hline$\beta_{M E}$ & - & - & - & - & -1.45 & -8.74 \\
\hline$\beta_{M L}$ & - & - & - & - & -3.23 & -9.88 \\
\hline$\theta$ & - & - & 0.43 & 6.25 & 0.36 & 5.49 \\
\hline VOT $^{*}($ Euro/h) & 29.46 & 4.14 & 5.20 & 1.30 & 10.56 & 2.48 \\
\hline VSDE* $^{*}$ (Euro/h) & 9.17 & 4.70 & 21.62 & 5.60 & 23.16 & 5.94 \\
\hline VSDL* (Euro/h) & 7.05 & 4.73 & 20.22 & 5.66 & 15.27 & 6.27 \\
\hline VSDME* (Euro/h) $^{*}$ & - & - & - & - & 8.76 & 5.26 \\
\hline VSDML* $^{*}$ Euro/h) & - & - & - & - & 19.54 & 5.61 \\
\hline Nr. Obs. & \multicolumn{2}{|c|}{1158} & \multicolumn{2}{|c|}{5965} & \multicolumn{2}{|c|}{5965} \\
\hline LogLik. & \multicolumn{2}{|c|}{-2673} & \multicolumn{2}{|c|}{-10550} & \multicolumn{2}{|c|}{-10410} \\
\hline Pseudo $\mathrm{R}^{2}$ & \multicolumn{2}{|c|}{0.17} & \multicolumn{2}{|c|}{0.36} & \multicolumn{2}{|c|}{0.37} \\
\hline $\begin{array}{l}{ }^{*} \text { The long-run and sh } \\
\text { VSDEs differ with a t } \\
\text { model, } \beta_{E} \text { differs fron } \\
\beta_{M L} \text { has a t-statistic }\end{array}$ & $\begin{array}{l}\text {-run } \\
\text { atisti }\end{array}$ & $\begin{array}{l}\text { Ts are sigr } \\
\text { f } 2.83 \text {, and } \\
\mathrm{h} \text { a t-statist } \\
\text { orthermore, }\end{array}$ & $\begin{array}{l}\text { itly di } \\
\text { SDLs }\end{array}$ & $\begin{array}{l}\text { rent with a } \\
\text { h a t-statist } \\
\text { ile the differ } \\
\text { between the }\end{array}$ & $\begin{array}{l}\text { istic of } \\
3.35 \text {. In } \\
\text { between } \\
\text { Ts in th }\end{array}$ & $\begin{array}{l}97, \text { the } \\
\text { he auxiliary } \\
\beta_{L} \text { and the } \\
\text { short-run }\end{array}$ \\
\hline
\end{tabular}

For all models, credible point estimates are obtained. The VOT is between 5.20 and 29.46 Euro/hour, the VSDE between 9.17 and 23.16 Euro/hour, and the VSDL between 7.05 and 20.22 Euro/hour. Significant differences between the long-run and the short-run estimates of the VOT, VSDE and VSDL confirm our main hypothesis that travelers have higher scheduling flexibility in the long run. ${ }^{15}$ We find that travel time is valued significantly higher in the long-run model than in the short-run model (where the travel time coefficient is insignificant), indicating that drivers attach a higher value to more permanent (repetitive) travel time changes, supposedly because these can be exploited better by rescheduling the routines. Schedule delays are valued much higher in the short-run model than in the long-run model. A likely explanation is the more binding nature of short-run scheduling

\footnotetext{
${ }^{15}$ Note that the standard errors of all valuations are computed using the Delta method (e.g. Small, 2012).
} 
constraints, which renders the re-planning of activities more costly. Moreover, the fact that $\theta$ is around 0.4 and significantly different from 0 , suggests that in the short run drivers indeed have more information on travel time realizations than in the long-run, and hence take this information into account when deciding on their departure time.

Since in the auxiliary model all scheduling coefficients are negative and significantly different from 0 , we can conclude that a net scheduling disutility results from moving away from the SRPAT towards the LRPAT. Therefore, the SRPAT is the valid anchor point of the short-run schedule delays. Specifically, we find that $\beta_{E}$ is significantly (about 2.6 times and with a t-statistic of 7.05) higher than $\beta_{M E}$. This indicates that schedule delay early is valued higher if one arrives early with respect to both preferred arrival times than in the intermediate domain, with earliness with respect to the SRPAT but lateness with respect to the LRPAT. While this finding might indicate that drivers still take into account the LRPAT in their departure time decisions, although to a lesser extent than the SRPAT, it may also reflect non-linearities in the valuation of earliness (e.g. Tseng and Verhoef, 2008). Regarding the coefficients for schedule delay late, we find that $\beta_{M L}$ is approximately 1.3 times larger than $\beta_{L}$ (with a t-statistic of 1.91). We can thus conclude that the costs of being late with respect to both the LRPAT and the SRPAT are comparable to the costs resulting from lateness with respect to the SRPAT but earliness with respect to the LRPAT. We also find that the VOT is higher in the auxiliary model compared to the short-run model (10.56 vs. 5.20 Euro), however, this difference is insignificant.

The next section discusses the robustness of the model specifications presented above.

\subsection{Robustness checks}

\subsubsection{General specification issues}

An essential property of the MNL model is the assumption on the independence of the estimates from adding or removing irrelevant alternatives (IIA). The IIA does not hold if decision makers regard some alternatives as closer substitutes than others in a way that is not captured by the explanatory variables. Using a Hausman-type test that has been suggested by Hausman and McFadden (1984), we compare the outcomes of the long-run and short-run models that only consider a sub-set of the originally available choice alternatives to the outcomes of the corresponding models that consider all available alternatives.

Dropping individual choice alternatives as well as combinations of them, we find that the IIA holds quite well for the long-run model. Although the formal test is rejected for some restricted choices sets, especially if alternatives close to the beginning or the end of the peak are left out, the resulting estimates for the VOT, the VSDE and the VSDL generally remain very close to those estimated in the main model.

For the short-run model, the IIA holds less well; it is rejected for all restricted choice sets that were tested. The most frequently used remedy if the IIA does not hold are nested logit models, which group those alternatives together (the so-called nests) that are considered close substitutes. The IIA must then hold within the nests, but not between 
them. However, our short-run choice problem does not lend itself easily to be transferred into a nested logit structure, since it is difficult to group the departure time alternatives according to substitutability. For instance, assuming that the nests group departure times by time-of-day, the latest scheduling alternative within the nest that groups early departures would still be expected to be a fairly good alternative for the earliest alternative within the subsequent nest. We therefore take a pragmatic approach and continue using MNL also for the short-run model. However, we ensure that our main results - that the short-run VOT is smaller than the long-run VOT and that the short-run VSDE and VSDL are higher than the corresponding long-run values - are not driven by the violation of the IIA assumption: among all the restricted choice sets investigated, we cannot identify any case where the implied result was such that the short-run VOT is significantly higher than the long-run VOT or the short-run schedule delay values are significantly lower than the long-run ones.

We also estimate various short-run and long-run models that included alternativespecific constants, in order to test whether our models are possibly misspecified in such a way that they do not capture time-of-day-specific characteristics. The constants are defined for increasingly larger groups of alternatives, taking into account the natural order of the alternatives by time-of-day. While for most long-run specifications we find these constants to be insignificant, for the short-run specifications the alternative-specific constants associated with very early departure time alternatives tend to be significantly negative. This additional disutility, which is not captured explicitly in our models, might be a consequence of commuters having a relatively high preference for being at home rather than at work in the early morning, as the work of Tseng and Verhoef (2008) suggests. The result that the VSDE becomes very similar to the VSDL if alternative-specific constants are considered, supports this explanation, since then in the main model the VSDE can be expected to capture the additional disutility from early departures. The unusual result of the main models - that the VSDE exceeds the VSDL - can thus possibly be attributed to the fact that our models do not allow for time-of-day-dependent scheduling preferences.

Next, we implement two tests to ensure that the measure of the LRPAT that we use is a good representation of the participants' preferred arrival time in their long-run choice of their SRPAT. The first test is based on the idea that the LRPAT must explain the SRPAT better than alternative measures of the LRPAT. For this purpose, we alter the LRPAT for all respondents by $[ \pm 5, \pm 10, \pm 15, \pm 20, \pm 25, \pm 30]$ minutes. Figure 2 shows that indeed the log-likelihood peaks very near the model where the LRPAT is left unchanged, confirming that the LRPAT, although drawn from a questionnaire, indeed seems to represent the drivers' most desired arrival time from a long-run perspective. In a second test, we divide the observations into two groups: the earliest 50 percent and the latest 50 percent of LRPATs. This is to check that the schedule delay cost valuations in the long-run model are not mainly due to early commuters (for schedule delay early), or mainly due to late commuters (for schedule delay late). Table 3 shows that a lower VOT, VSDE and VSDL are obtained for the earlier LRPATs compared to the later LRPATs, however, the differences turn out to be insignificant. 
Figure 2: $\operatorname{LRPAT} \pm \mathrm{x}$ minutes

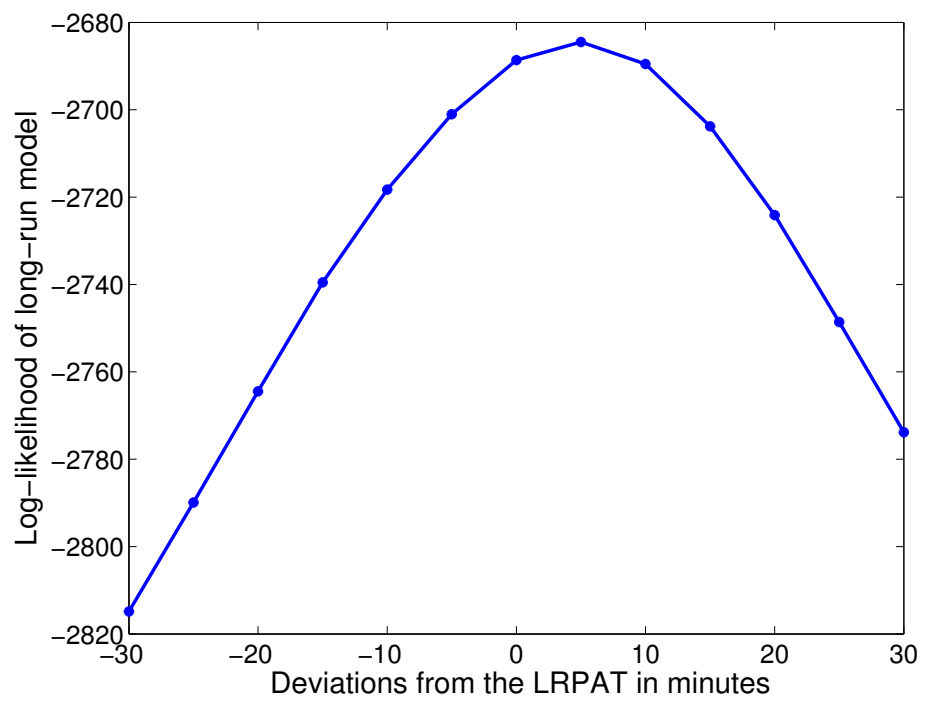

Additionally, we perform two robustness checks for the short-run model. For the first one, we re-estimate the short-run model as presented in Table 2, with the only difference that travel time expectations are assumed equal to the actual travel time realizations (hence, $\theta=1$ ) instead of a weighted average between the actual realizations and the weekday-specific average. If this model yields similar results as the main short-run model, we can conclude that the estimation results of the main short-run model are not driven by long-run travel time expectations. If the latter was true, differences between long-run arrival routines and actual arrival times would be due to unobserved factors only, rendering the distinction between the long-run and the short-run model meaningless. The estimation results in Table 3 show that similar values of schedule delay as in the main short-run model are obtained (with the differences being insignificant). This is an indication that actual travel time realizations are able to explain short-run behavior, although slightly less well than the short-run model. The latter finding provides an argument for still including the long-run travel time expectations as part of the short-run expectations (i.e. $\theta<1$ ), since they assume the role of a stabilizing element in the formation of short-run travel time expectations.

In the second robustness check that specifically concerns the short-run model, we test whether the particular shape of the SRPAT distribution over the time of the day, with a large share of drivers departing before the peak (Figure 1d), might possibly drive the estimation result. For this purpose, we re-estimate the short-run model while applying weights to the observations that are defined as inversely proportional to the density of 
the SRPAT distribution. ${ }^{16}$ The corresponding results are presented in Table 3. We find that the VOT, VSDE and VSDL are not significantly different from those derived in the standard short-run model, and can thus conclude that the estimation results are not driven by the uneven distribution of departure times over the time of the day.

Table 3: Robustness checks: General (MNL)

\begin{tabular}{|c|c|c|c|c|c|c|c|c|}
\hline \multirow[b]{3}{*}{ Coefficient } & \multicolumn{4}{|c|}{ Long-run } & \multicolumn{4}{|c|}{ Short-run } \\
\hline & \multicolumn{2}{|c|}{ Early LRPAT } & \multicolumn{2}{|c|}{ Late LRPAT } & \multicolumn{2}{|c|}{$\theta=1$} & \multicolumn{2}{|c|}{ Inverse Density } \\
\hline & Value & t-Stat. & Value & t-Stat. & Value & t-Stat. & Value & t-Stat. \\
\hline$\beta_{R}$ & 0.23 & 3.61 & 0.15 & 2.05 & 0.15 & 7.36 & 0.15 & 6.33 \\
\hline$\beta_{T}$ & -5.59 & -4.59 & -7.18 & -5.45 & -0.13 & -0.50 & -0.05 & -0.13 \\
\hline$\beta_{E}$ & -1.80 & -5.72 & -2.09 & -10.67 & -2.80 & -19.19 & -2.70 & -20.84 \\
\hline$\beta_{L}$ & -1.57 & -10.20 & -1.48 & -7.06 & -2.65 & -21.50 & -2.69 & -19.48 \\
\hline$\theta$ & - & - & - & - & 1 & - & 0.47 & 8.33 \\
\hline VOT $^{*}($ Euro/h) & 23.97 & 2.85 & 47.10 & 2.02 & 0.88 & 0.32 & 0.36 & 0.08 \\
\hline VSDE* $^{*}($ Euro/h) & 7.76 & 3.13 & 13.74 & 2.13 & 19.20 & 7.00 & 18.30 & 6.08 \\
\hline VSDL* (Euro/h) & 6.72 & 3.48 & 9.68 & 2.08 & 18.14 & 7.11 & 18.18 & 6.05 \\
\hline Nr. Obs. & \multicolumn{2}{|c|}{579} & \multicolumn{2}{|c|}{579} & \multicolumn{2}{|c|}{5965} & \multicolumn{2}{|c|}{5965} \\
\hline LogLik. & \multicolumn{2}{|c|}{-1269} & \multicolumn{2}{|c|}{-1409} & \multicolumn{2}{|c|}{-10592} & \multicolumn{2}{|c|}{-10871} \\
\hline Pseudo $\mathrm{R}^{2}$ & \multicolumn{2}{|c|}{0.21} & \multicolumn{2}{|c|}{0.12} & \multicolumn{2}{|c|}{0.36} & \multicolumn{2}{|c|}{0.34} \\
\hline
\end{tabular}

${ }^{*}$ Comparing the two long-run models, the corresponding differences between the VOTs, VSDEs and VSDLs are insignificant. The same holds for the differences in the valuations between the short-run models presented in this table and the main model presented in Table 2.

\footnotetext{
${ }^{16}$ The density of the SRPAT distribution is calculated using a normal kernel function with a bandwidth of 15 minutes.
} 


\subsubsection{Travel time variability}

We were not able to estimate the cost of travel time variability in the long-run model, due to the strong correlation between the standard deviation of travel times and average travel times, which is a common pattern (e.g. Peer et al., 2012). A consequence may be that the relatively high VOT in the long-run model partially reflects the value attached to reliability, and thus to short-run schedule delays. To check whether the difference between the long-run and the short-run VOT persists if we correct for this, we impute the share of the long-run VOT that may be due to variability. For this purpose, we use the relationship between the valuation of reliability (VOR) and the valuation of schedule delays that was established by Noland and Small (1995) and later generalized by Fosgerau and Karlström (2010). Fosgerau and Karlström (2010) showed that for any standardized travel time distribution that is constant over the time of the day, the VOR attached to the regarding travel time distribution $\Phi$ is given by

$$
\mathrm{VOR}=(\mathrm{VSDE}+\mathrm{VSDL}) H\left(\Phi, \frac{\mathrm{VSDE}}{\mathrm{VSDE}+\mathrm{VSDL}}\right),
$$

where $H(\Phi, \mathrm{VSDE} /(\mathrm{VSDE}+\mathrm{VSDL}))$ is the so-called mean lateness factor, which is equal to the average lateness conditional on being late. The costs of variability provided that the travel time distribution $\Phi$ has standard deviation $\sigma$ are then given by $\sigma$ VOR.

To approximate the long-run VOR, we derive for each driver a standardized travel time distribution $\Phi_{z}$ and mean lateness factor $H\left(\Phi_{z}, \mathrm{VSDE} /(\mathrm{VSDE}+\mathrm{VSDL})\right)$, using the VSDE and VSDL derived in the short-run model. ${ }^{17}$ These can be interpreted as the values attached to rather incidental variations of travel time and they therefore represent an upper limit to the valuation of travel time variability in the long run. We compute the costs of variability that arise if travel time changes by one hour, in order to be able to compare them directly to the VOT. Therefore, we multiply the VOR by the derivative $(\partial \sigma / \partial E[T])_{z}$, which is computed using a simple OLS regression. On average, $(\partial \sigma / \partial E[T])_{z}$ is found equal to 0.54 , indicating the positive correlation between mean travel time and travel time variability. We then find that the average driver-specific costs of variability that result when the expected travel time changes by 1 hour is equal to 16.71 Euro. The costs are fairly similar across drivers, with a standard deviation amounting to 1.00 Euro. We can therefore conclude that about half of the long-run VOT as presented in Table 2 should be attributed to the costs resulting from travel time variability. Even after removing these costs of variability, the long-run VOT of 13.45 Euro still exceeds the short-run VOT.

\footnotetext{
${ }^{17}$ For each driver we form a standardized travel time distribution based on the long-run travel time expectations for each of the $J$ departure time intervals. The assumption that travel time distributions are constant over the time of the day is not perfectly fulfilled. However, it was verified that our results hold also if standardized travel times are based either on peak or off-peak travel time distributions only.
} 


\subsubsection{Observed heterogeneity and self-selection}

In our main models, we do not include any variables that describe driver-specific characteristics, the main reason being that barely any of them were found significant. We tested interactions with the reward, time and schedule delay coefficients (both simultaneously and sequentially) for the following socio-economic characteristics: income ${ }^{18}$, education, gender, age, presence and age of children, and household structure. We could not find any interactions that were significant at the 5 percent level in the short-run model. In the long-run model the only significant interactions we could identify were that schedule delays are valued lower by persons with either a relatively low or high income, and higher by persons with low education. However, since the size of these effects is fairly small, we prefer to present here the simpler models that ignore observed heterogeneity between participants.

Drivers could self-select themselves for participation in the experiment, rendering participants potentially different from non-participants. While this paper does not aim at providing representative valuations for a larger group than the group of participants considered in the analysis, not in the least place because it is ambiguous how such a larger group should be defined, we intend to test whether there is any indication that the relations we find between the short-run and long-run valuations of travel time and schedule delay might only hold for participants but not for non-participants.

To see whether and how participants and non-participants differ, a small-scale survey (84 valid answers) was carried out among those who were invited to participate in the experiment but decided not to do so. We used the data on those variables that have been collected for both participants and non-participants to run a simple logit model that seeks to explain which variables drive participation. We found that a higher likelihood of participation applies for persons with high education, persons who travel frequently along the $\mathrm{C} 1-\mathrm{C} 2$ link during peak hours before the start of the experiment, and persons with usual work starting times before 7:30 and after 8:30. Females and older persons, as well as people who state they have no flexibility of starting earlier and/or later than usual are relatively more likely to decide against participation. Income, household structure, the presence and age of kids as well as a constant term were not found significant.

Using the propensity scores (the fitted values) from the logit model, we are able to test whether also for participants with a low propensity score (hence, those that are most similar to non-participants) the long-run VOT is higher than the short-run VOT, and the long-run valuations of schedule delays are lower than the short-run ones. We therefore re-run the standard long-run and short-run models including only participants in the lower

\footnotetext{
${ }^{18}$ As the (ordinal) income variable collected from a questionnaire does not exhibit a large degree of variation across drivers and is furthermore not available for all drivers considered in our analyses, we also tested a second income measure, which is derived from matching the ZIP code area a participant has reported to live in with the average incomes (in 2008) in the same ZIP code area. We use 6-digit ZIP code areas, which in our sample are composed of ca. 60 households each.
} 
30th and the lower 50 th percentile of propensity scores. ${ }^{19}$ As Table 4 shows, the estimation

Table 4: Robustness checks: Propensity scores for participation (MNL)

\begin{tabular}{|c|c|c|c|c|c|c|c|c|}
\hline \multirow[b]{3}{*}{ Coefficient } & \multicolumn{4}{|c|}{ Long-run } & \multicolumn{4}{|c|}{ Short-run } \\
\hline & \multicolumn{2}{|c|}{ 30th percentile } & \multicolumn{2}{|c|}{ 50th percentile } & \multicolumn{2}{|c|}{ 30th percentile } & \multicolumn{2}{|c|}{ 50th percentile } \\
\hline & Value & t-Stat. & Value & t-Stat. & Value & t-Stat. & Value & t-Stat. \\
\hline$\beta_{R}$ & 0.15 & 1.91 & 0.20 & 3.29 & 0.11 & 2.37 & 0.11 & 3.39 \\
\hline$\beta_{T}$ & -6.93 & -3.74 & -5.91 & -5.91 & -0.95 & -0.83 & -0.81 & -1.09 \\
\hline$\beta_{E}$ & -2.35 & -7.52 & -2.05 & -8.38 & -3.13 & -11.50 & -2.86 & -13.58 \\
\hline$\beta_{L}$ & -1.91 & -7.88 & -1.71 & -10.52 & -2.75 & -13.16 & -2.63 & -14.79 \\
\hline$\theta$ & - & - & - & - & 0.31 & 2.73 & 0.37 & 4.22 \\
\hline VOT* $^{*}($ Euro/h) & 47.62 & 1.70 & 29.19 & 2.63 & 8.63 & 0.74 & 7.39 & 0.98 \\
\hline $\operatorname{VSDE}^{*}($ Euro/h) & 16.20 & 1.86 & 10.14 & 3.07 & 28.30 & 2.17 & 26.02 & 3.22 \\
\hline VSDL* $^{*}$ Euro/h) & 13.08 & 1.86 & 8.43 & 3.15 & 24.91 & 2.18 & 23.89 & 3.24 \\
\hline Nr. Obs. & \multicolumn{2}{|c|}{323} & \multicolumn{2}{|c|}{539} & \multicolumn{2}{|c|}{1656} & \multicolumn{2}{|c|}{2778} \\
\hline LogLik. & \multirow{2}{*}{\multicolumn{2}{|c|}{-711}} & \multicolumn{2}{|c|}{-1229} & \multicolumn{2}{|c|}{-2928} & \multicolumn{2}{|c|}{-4965} \\
\hline Pseudo $\mathrm{R}^{2}$ & & & \multicolumn{2}{|c|}{0.18} & \multicolumn{2}{|c|}{0.36} & \multicolumn{2}{|c|}{0.35} \\
\hline
\end{tabular}

results confirm that the main findings of the paper hold also for the participants that are most similar to non-participants. We therefore conclude that although self-selection is clearly evident for this experiment, it does not seem to have strong implications for the relation between long-run and short-run valuations of time and schedule delays.

\subsubsection{Unobserved heterogeneity}

We estimate panel latent class models in order to investigate whether the results differ from the main models in Table 2 if we account for unobserved heterogeneity among drivers. We re-estimate the main long-run and short-run models allowing for two latent $\operatorname{classes}^{20}$ in both models. While various formulations are possible for the class membership model, we adopt a simple multinomial logit form here (without additional explanatory variables ${ }^{21}$

\footnotetext{
${ }^{19}$ Note that we could also have used lower percentiles than the 30th. However, then, probably as a consequence of the small sample size, the reward coefficient becomes insignificant leading to meaningless point estimates of the valuations. Regardless of that, also for lower percentile values, we still find that in the long-run model, the time coefficient is higher in absolute terms than the schedule delay coefficients; and the other way round for the short-run model.

${ }^{20}$ We tested also higher numbers of classes, however, found that the estimated coefficients become fairly unstable.

${ }^{21}$ We also tested a panel latent class model with class membership being conditional on various socioeconomic characteristics. However, given that the corresponding coefficients turned out insignificant in the MNL models, it is not surprising that we obtained a similar result for the latent class models.
} 
other than a constant), which ensures that relative class sizes sum up to 1 without actively constraining the parameter values in the estimation.

As Table 5 shows, the log-likelihood improves significantly compared to the MNL estimates (from Table 2) for both the long-run and the short-run model.

Table 5: Results: Latent class models

\begin{tabular}{|c|c|c|c|c|c|c|c|c|}
\hline \multirow[b]{3}{*}{ Coefficients } & \multicolumn{4}{|c|}{ Long-Run } & \multicolumn{4}{|c|}{ Short-Run } \\
\hline & \multicolumn{2}{|c|}{ Class 1} & \multicolumn{2}{|c|}{ Class 2} & \multicolumn{2}{|c|}{ Class 1} & \multicolumn{2}{|c|}{ Class 2} \\
\hline & Value & t-Stats. & Value & t-Stats. & Value & t-Stats. & Value & t-Stats \\
\hline$\beta_{R}$ & 0.25 & 2.62 & 0.11 & 2.61 & 0.16 & 4.49 & 0.12 & 3.84 \\
\hline$\beta_{T}$ & -10.34 & -5.30 & -7.22 & -7.44 & -0.63 & -0.93 & -1.21 & -1.29 \\
\hline$\beta_{E}$ & -1.35 & -3.37 & -4.80 & -11.55 & -1.56 & -11.10 & -5.68 & -16.55 \\
\hline$\beta_{L}$ & -4.13 & -5.02 & -1.49 & -15.85 & -1.46 & -11.33 & -5.00 & -15.55 \\
\hline$\theta$ & - & - & - & - & 0.73 & 3.43 & 0.48 & 10.20 \\
\hline Class Prob. & 0.32 & 5.06 & 0.68 & 10.74 & 0.45 & 10.44 & 0.55 & 12.76 \\
\hline VOT (Euro/h) & 41.20 & 2.03 & 64.46 & 1.74 & 3.86 & 0.81 & 10.00 & 1.07 \\
\hline VSDE (Euro/h) & 5.40 & 2.89 & 42.86 & 2.09 & 9.63 & 3.50 & 49.94 & 3.94 \\
\hline VSDL (Euro/h) & 16.52 & 2.39 & 13.30 & 2.12 & 9.01 & 3.63 & 41.32 & 3.92 \\
\hline Nr. Obs. & \multicolumn{4}{|c|}{1158} & \multicolumn{4}{|c|}{5965} \\
\hline LogLik. & \multirow{2}{*}{\multicolumn{4}{|c|}{$\begin{array}{c}-2494 \\
022\end{array}$}} & \multirow{2}{*}{\multicolumn{4}{|c|}{$\begin{array}{r}-9887 \\
0.40\end{array}$}} \\
\hline Pseudo $R^{2}$ & & & & & & & & \\
\hline
\end{tabular}


As in the corresponding MNL models, travel time is valued higher than schedule delays in the long run, and the reverse relation holds for the short run. The VOT is larger in the long run compared to the short run, which is consistent with the MNL results. Regarding the schedule delay valuations, the evidence from the latent class model is a bit more mixed. While the (cross-class) average short-run schedule delays are higher than the long-run ones (consistent with the MNL results), the latent class model suggests that at least for some drivers the long-run and the short-run valuations of schedule delays might not be significantly different across the two time dimensions. As this does not imply that the relationship between long-run and short-run schedule delay values is reverse and thus contradictory to the MNL estimation results, we can still conclude that the main results remain robust when accounting for unobserved heterogeneity between drivers.

Finally, note that it is not necessary for the latent class estimates to yield average values (weighted by the class probabilities) that are close to the point estimates of the MNL models for various reasons, including correlations between the variables, differences in the variances of the estimates, and non-linearities.

\section{Conclusions}

We decompose the morning scheduling decisions of car commuters into long-run choices of arrival routines and short-run choices of departure times subject to the routines chosen in the long run. For this purpose, we use revealed preference (RP) data from a large-scale peak avoidance experiment in the Netherlands. In their scheduling choices, participants of the experiment trade off expected travel times, schedule delays (arriving earlier or later than preferred) and (time-of-day dependent) monetary rewards. Travel time expectations are more accurate in the short run than in the long run, since updated travel time information for the day of travel becomes available in the short run. The main goal of this paper is to investigate whether these differences between long-run and short-run scheduling decisions are reflected in different valuations of travel time and schedule delays across the two time dimensions.

The data have been collected during a real-life peak-avoidance experiment, where participants were able to gain monetary rewards for not using a specific, frequently congested highway link during the morning rush hour over a period of almost 4 months. We find that commuters indeed attach different values to the attributes of their scheduling alternatives in the long run compared to the short run: Travel times are valued substantially higher in the long run, while schedule delays are valued much higher in the short run. These findings are consistent with the intuitive notion that travel time gains can be exploited better in the long run through the adaptation of routines, while scheduling constraints are more binding in the short run when routines are fixed.

Our results may have substantial impacts on optimal choices for transport policies such as pricing and investment. Most evidently, they suggest that different values of time and schedule delay should be used in the evaluation of policy options, depending on whether 
they lead to permanent changes in travel times (e.g. road capacity expansions) or changes in travel times that occur only under certain circumstances (e.g. incident management). Our results may also motivate research on the distinction between long-run and shortrun scheduling decisions in the context of equilibrium transport models. A first study by Peer and Verhoef (2013), which is based on Vickrey's bottleneck model, underlines this by showing that the pricing instruments required to reach the social optimum differ considerably from the standard (short-run) solution of the bottleneck model once the distinction between long-run and short-run scheduling preferences is taken into account.

Follow-up research should also focus on confirming the external validity of the results obtained in this paper. This is particularly important, as participation in the peakavoidance experiment was not random; instead, commuters invited for participation could decide in favor or against it. As a consequence, it can be shown that participants differ from non-participants along various dimensions. While we investigate the implications of such self-selection behavior on the main results obtained in this paper, and find them to be minor, replication of our modeling approach and the corresponding results in different contexts would clearly underline the relevance of the findings presented here.

As the collection of RP data tends to be quite challenging and expensive, one could try to use stated preference (SP) data in future studies on long-run and short-run scheduling decisions. SP data have the advantage that the researcher is in control of the choice set, the attribute values of the choice alternatives as well as the correlations between them. Therefore it may for instance be feasible with SP data to estimate the value attached to travel time reliability directly, unlike with the RP data used here. Nevertheless a main challenge remains, and that is to phrase and frame the SP experiment such that respondents interpret the choice situations in the same way as intended by the researcher (hence, either as long-run or short-run choice), and react to it as they would react in reality. The latter is a generic concern related to SP data, including those collected for the analysis of travel behavior (e.g. Hensher, 2010).

\section{Affiliations}

Stefanie Peer: VU University Amsterdam, The Netherlands, Vienna University of Economics and Business, Austria

Erik Verhoef: VU University Amsterdam, The Netherlands, Tinbergen Institute, The Netherlands

Jasper Knockaert: VU University Amsterdam, The Netherlands

Paul Koster: VU University Amsterdam, The Netherlands, Tinbergen Institute, The Netherlands

Yin-Yen Tseng: Southwestern University of Finance and Economics, China 


\section{References}

Asensio, J. And A. MAtas, "Commuters' valuation of travel time variability," Transportation Research Part E: Logistics and Transportation Review 44 (2008), 1074-1085.

Becker, G., "A Theory of the Allocation of Time," The Economic Journal 75 (1965), 493-517.

BÖRJESSON, M., "Joint RP-SP data in a mixed logit analysis of trip timing decisions," Transportation Research Part E: Logistics and Transportation Review 44 (2008), 10251038.

- "Modelling the preference for scheduled and unexpected delays," Journal of Choice Modelling 2 (2009), 29-50.

BörJesson, M., J. Eliasson AND J. Franklin, "Valuations of travel time variability in scheduling versus mean-variance models," Transportation Research Part B: Methodological 46 (2012), 855-873.

Carrion, C. and D. Levinson, "Value of travel time reliability: A review of current evidence," Transportation research Part A: Policy and practice 46 (2012), 720-741.

Daly, A., S. Hess And C. ECKERT, "Workshop report: working with repeated choice data," in S. Hess and A. Daly, eds., Choice Modelling: The State of the Art and the State of Practice (Cheltenham, UK: Edward Elgar Publishing, 2013), 91-106.

DeSerpa, A., "A theory of the economics of time," The Economic Journal 81 (1971), 828-846.

Evans, R., "Central London Congestion Charging Scheme: Ex-post evaluation of the quantified impacts of the original scheme," , Congestion Charging Modelling and Evaluation Team, London, UK, 2007, http://www.tfl.gov.uk/assets/downloads/ Ex-post-evaluation-of-quantified-impacts-of-original-scheme-07-June.pdf.

Fosgerau, M. And A. Karlström, "The value of reliability," Transportation Research Part B: Methodological 44 (2010), 38-49.

Gaver, D., "Headstart strategies for combating congestion," Transportation Science 2 (1968), 172-181.

Greene, W. And D. Hensher, "A latent class model for discrete choice analysis: Contrasts with mixed logit," Transportation Research Part B: Methodological 37 (2003), 681-698.

Hausman, J. and D. MCFAdDen, "Specification tests for the multinomial logit model," Econometrica: Journal of the Econometric Society (1984), 1219-1240. 
Hendrickson, C. And E. Plank, "The flexibility of departure times for work trips," Transportation Research Part A: General 18 (1984), 25-36.

Hensher, D., "Measurement of the valuation of travel time savings," Journal of Transport Economics and Policy 35 (2001), 71-98.

, "Hypothetical bias, choice experiments and willingness to pay," Transportation Research Part B: Methodological 44 (2010), 735-752.

Hollander, Y., "Direct versus indirect models for the effects of unreliability," Transportation Research Part A: Policy and Practice 40 (2006), 699-711.

KNiGHT, T., "An approach to the evaluation of changes in travel unreliability: A 'safety margin' hypothesis," Transportation 3 (1974), 393-408.

Knockaert, J., D. Ettema, E. Verhoef, P. Koster, S. Peer and Y. Tseng, "Spitsmijden Gouda-Zoetermeer," http://www.spitsmijden.nl/downloads/ SM2D_scientific_report_final.pdf, 2012a.

Knockaert, J., Y.-Y. Tseng, E. T. Verhoef and J. Rouwendal, "The Spitsmijden experiment: A reward to battle congestion," Transport Policy 24 (2012b), 260-272.

Lam, T. And K. Small, "The value of time and reliability: measurement from a value pricing experiment," Transportation Research Part E: Logistics and Transportation Review 37 (2001), 231-251.

Li, Z., D. Hensher And J. Rose, "Willingness to pay for travel time reliability in passenger transport: A review and some new empirical evidence," Transportation Research Part E: Logistics and Transportation Review 46 (2010), 384-403.

McFadden, D., "Conditional Logit Analysis of Qualitative Choice Behavior," in P. Zarembka, ed., Frontiers in econometrics (New York: Academic Press, 1974), 105-142.

Noland, R. And K. Small, "Travel-time uncertainty, departure time choice, and the cost of the morning commute," Paper presented at the 74th annual meeting of the Transportation Research Board, Washington (1995).

Peer, S., J. Knockaert, P. Koster, Y. Tseng and E. Verhoef, "Door-to-Door Travel Times in RP Departure Time Choice Models. An Approximation Method based on GPS Data," Transportation Research Part B: Methodological 58 (2013), 134-150.

Peer, S., C. Koopmans And E. Verhoef, "Prediction of travel time variability for cost-benefit analysis," Transportation Research Part A: Policy and Practice 46 (2012), 79-90. 
Peer, S. And E. T. Verhoef, "Equilibrium at a bottleneck when long-run and short-run scheduling preferences diverge," Transportation Research Part B: Methodological 57 (2013), 12-27.

POLAK, J., "Travel time variability and departure time choice: A utility theoretic approach," Discussion Paper 15, Transport Studies Group, University of Westminster (previously Polytechnic of Central London) (1987).

Shires, J. AND G. De Jong, "An international meta-analysis of values of travel time savings," Evaluation and Program Planning 32 (2009), 315-325.

Small, K., "The scheduling of consumer activities: Work trips," The American Economic Review 72 (1982), 467-479.

- Valuation of travel-time savings and predictability in congested conditions for highway user-cost estimation, NCHRP Report 431 (Transportation Research Board, 1999).

_, "Valuation of travel time," Economics of Transportation 1 (2012), 2-14.

Small, K. And E. Verhoef, The economics of urban transportation (London, UK: Routledge, 2007).

Small, K. A., C. Winston And J. Yan, "Uncovering the distribution of motorists' preferences for travel time and reliability," Econometrica 73 (2005), 1367-1382.

Tseng, Y. And E. Verhoef, "Value of time by time of day: A stated-preference study," Transportation Research Part B: Methodological 42 (2008), 607-618.

Tseng, Y.-Y., J. KNockAert And E. T. Verhoef, "A revealed-preference study of behavioural impacts of real-time traffic information," Transportation Research Part C: Emerging Technologies 30 (2013), 196-209.

Van Ommeren, J. And M. Fosgerau, "Workers' marginal costs of commuting," Journal of Urban Economics 65 (2009), 38-47.

Van Ommeren, J., G. Van Den Berg and C. Gorter, "Estimating the marginal willingness to pay for commuting," Journal of Regional Science 40 (2000), 541-563.

Vickrey, W. S., "Congestion theory and transport investment," The American Economic Review 59 (1969), 251-260.

Wardman, M., "A review of British evidence on time and service quality valuations," Transportation Research Part E: Logistics and Transportation Review 37 (2001), 107-128. 
Zamparini, L. And A. RegGiani, "Meta-analysis and the value of travel time savings: A transatlantic perspective in passenger transport," Networks and Spatial Economics 7 (2007), 377-396. 